\title{
Sociability Between Coworkers and Social Fit
}

\author{
at Work
}

\author{
Thomas Lyttelton
}

\begin{abstract}
Social interactions vary across workplaces, in part because workers and managers treat informal social interactions as a facet of workplace cultures, encouraging it in some instances and suppressing it in others. Equally, such interactions are consequential for social capital, and may be a dimension of cultural fit. Thus processes of status attainment and resource allocation may vary across workplaces in concert with their sociability. Using a new measure of time spent with coworkers, constructed using the American Time Use Survey, this paper shows that work explains a great deal more variation in sociability between coworkers than individual characteristics. The extent of shared workplace identities, influenced by occupational competition levels and union membership, and incentives to socialize are two important mechanisms in this process. Moreover, norms and expectations of appropriate behavior in the workplace accompany occupational differences in sociability, and matching these expectations is consequential for workers' earnings.
\end{abstract}

\section{Introduction}

Both workers and managers treat informal social interactions as an important facet of workplace cultures, encouraging it in some instances and suppressing it in others (Halle 1984, 
Kunda 2009, Reich and Bearman 2018, Richman 2015) At the same time, workers understand sociable interactions with other workers to be fundamentally different to sociable interactions without an instrumental component (Fischer 1982, Ingram and Zou 2008). In this, they have good cause, as both individual social relations and the broader workplace social context influence a number of important worker and organizational outcomes, both positive and negative, including job satisfaction, human capital accrual, and harassment (Baillien et al. 2008, Morrison 2012, Roscigno et al. 2018). Processes of status attainment and resource allocation thus may vary across workplaces in concert with sociability, yet we know little about how sociability varies across occupations and organizations.

The dominant approach to studying sociability in workplaces has been the social networks paradigm, which treats interactions as ties. This is well suited to illuminating both the individual and relational determinants of interactions, but usually abstracts away the organizational context in which the interaction took place (Burt 1992, McPherson et al. 2001, Podolny and Baron 1997). This is often a necessity, as most network data comes from a single organization, limiting contextual variation in the data. This is also true of workplace ethnographies, for which, in any case, "coworker relations have held at best a secondary place in the analysis of the workplace", (Hodson 2001: 202).

In contrast, research on culture and work has been finely attuned to the role of contextual variation in influencing behavior, but has rarely considered informal social interactions. This literature considers, first, the contextual antecedents to organizational norms (Chandler et al. 2000), second, the role of organizational norms in directing workers' behavior (Burawoy 1982, Chatman and O'Reilly 2016), and third, the consequences of relational fit of the worker to the job or organization (Mobasseri et al. 2019, Srivastava et al. 2018). Yet despite documenting the importance organizations place on sociability (Kunda 2009, Richman 2015, Rivera 2012), research in this vein has considered neither the contextual determinants of workplace sociability nor the consequences of this sociability for workers. 
I explore the contextual determinants of coworker sociability and its consequences for workers' earnings, using a novel measure of coworker sociability - the amount of time workers spend socializing with coworkers - derived from the American Time Use Survey (ATUS). As a time diary study, ATUS contains fine-grained distinctions between social contexts, such as between sociability in and outside of the workplace, detailed measures of work patterns, such as irregular schedules and work breaks, and affectual data. As a module of the Current Population Survey (CPS), ATUS also includes a number of job, workplace, and occupation measures.

I find that sociability is highly sensitive to context: different activity partners, locations, and occupations all create starkly different patterns of interaction. At the same time, coworker sociability is strongly influenced by organizational and occupational characteristics: coworkers socialize at higher rates when their sense of shared identity is strong, in, for example, less competitive and unionized workplaces, and when there are strong instrumental incentives to socialize. Overall, work explains much more of the variation in coworker sociability than individual characteristics, such as marital status and care work responsibilities. Work patterns in coworker sociability, in turn, produce sociability expectations that are consequential for earnings: in highly sociable occupations, the earnings of sociable workers are higher than they are in less sociable occupations. This suggests that sociability between coworkers is a facet of cultural fit.

\section{Theory}

The following three sections argue that sociability between coworkers is important both for workers and workplaces, and that it is distinct from and often more difficult than sociability in

other contexts. As such, it is distinctively driven by workplace processes. The first section lays out that sociability flourishes when in egalitarian, volitional, and non-instrumental contexts, 
and so often is in tension with work, which is often none of these things. Because of this tension, workers often conceptualize sociability with coworkers as different to other kinds of sociability. The second section argues that, as a work-inflected phenomenon, sociability between coworkers is driven by workplace mechanisms, and suggests three important ones: coordination costs, incentives, and preference-shaping. Coworker sociability may be consequential for workers and workplaces, and this is discussed in the third section. Socializing is a precursor of social capital, and sociability likely clusters by work context. These aggregate behavioral differences may be accompanied by cultural norms and expectations, and thus be a dimension of cultural fit.

\section{The Sociology of Sociability}

Humans are motivated by a need to belong, satisfying which requires relationships and interactions (Baumeister and Leary 1995, Nezlek et al. 2002). That is, people require frequent, pleasant interactions in the context of affectually-positive relationships. At first glance, coworkers are an ideal source for such interactions: people spend a long time at work, where they are, usually, exposed to a stable set of coworkers, with whom they have at least one thing in common. For many workers, work provides such social relations. In the General Social Survey, 18-29\% of respondents list a coworker as a confidant and workplace ethnographies detail the ways in which workers intersperse work tasks with sociability (Halle 1984, Hodson 2001, McPherson et al. 2006).

Yet workers across diverse jobs report finding socializing with coworkers fraught. In response to a comment that publishing was founded on a "phony sense of community," a publicity director bursts into tears (Coser et al. 1982, quoted in Ingram and Zou 2008). Kunda (2009) reports employees at a technology firm classifying socializing with coworkers as "work,". Jackall quotes a bank clerk explaining that she goes to the company party because "if I don't, they'll talk about me" (1978, quoted in Hodson 2001), and in his meta-analysis of 
workplace ethnographies, Hodson (2001) finds conflict between coworkers to be pervasive. These reactions are found whether or not socializing takes place at work or outside the workplace, as in above examples. These reactions therefore probably do not reflect either tension with work tasks, or managerial disapproval.

Georg Simmel draws an analogy between sociability and play. He argues that, like play, successful sociability requires insulation from both the cognitive orientations and social contexts of normal life, particularly instrumental motives and external roles (Simmel and Hughes 1949). Instrumental motives introduce a set of cognitive orientations routed in quotidian life, while external roles, such as those of supervisor and supervisee, come with obligations and interactional norms that detract from the playful nature of sociability.

Simmel's account has been criticized by Irving Goffman (1972), for his insistence that sociability is devoid of status differentials, when sociable situations, such as parties, often include status jockeying. But the existence of status play within sociability is not necessarily inconsistent with the tension between sociability and external motivations and roles. As Alice Goffman points out, people rarely enjoy status jockeying in social situations (Goffman 2019), and diary studies on the relationship between interaction and psychological wellbeing suggests that sociable interactions are more pleasant when people feel they have autonomy over a situation (Downie et al. 2008, Nezlek 2003).

Simmel's criteria shows why workers often dislike socializing with coworkers. First, work introduces a set of instrumental motives. Social relations are important for many individual work outcomes (Castilla 2005, Fernandez et al. 2000, Podolny and Baron 1997, Shwed and Kalev 2014), and popular culture promotes networking (Carnegie 1933, Ferrazzi and Raz 2005). In response, some workers instrumentally cultivate social relationships (Ingram and Zou 2008). But instrumental motivations for coworker sociability extend beyond individual outcomes: leaders often promote social events to develop or maintain a "strong culture" (Berman et al. 2002, Kunda 2009), while some ethnographers report teams using social 
interactions to test job suitability (Halle 1984).

Second, workers struggle with role ambiguity. Workers may be uncertain of the motives of their socializing coworkers. It also may be unclear to workers whether to follow the interactional norms that apply to socializing or work, which are often in tension (Pillemer and Rothbard 2018). Some coworkers resolve this by socializing minimally, or insisting on classifying some social events as "work" (Kunda 2009). Relatedly, people are more reluctant to conceptualize a relationship as a friendship when there is a preexisting instrumental relationship, such as working together (Fischer 1982).

Similarly, some status roles really are incompatible with sociability, as Simmel argues. It would, for example, be a violation of the norm that sociability is volitional for a manager to order one of their employees to get them a drink in a social setting, for example. Yet the setting aside of status differentials is not straightforward, and workers may feel obliged to socialize because those in positions of power over them are doing so. Thus, sociability between coworkers is likely experientially distinct from other kinds of sociability. Role ambiguity introduces uncertainty about appropriate interactional norms, while the incentive to pursue instrumental ends through sociable means leaves parties second guessing the intentions of each other. More broadly, sociability is highly sensitive to context, with the setting and pre-existing relationships between actors influencing the valence of the interaction.

\section{Work Contexts and Sociability}

If sociability between coworkers is a work-inflected phenomenon, then it is likely to also be distinctly structured by work contexts. Differences in rates of sociability between coworkers by work context may be the result of three sets of mechanisms, laid out in Table 1. First, work may influence the coordination of interaction between coworkers. Interactions require time, a location, and at least two actors, all of which work may determine. Second, workers in different contexts may be differientially motivated to socialize for motivations intrinsic to 
sociability. This may be because sociable workers select into jobs, or because work shapes preferences. Third, there are differences in the extrinsic incentives to socialize between work contexts. Some jobs expect sociability, while others do not, and there is variation in the capacity to enforce these expectations. At the same time, social capital is differentially important across jobs.

Researchers use "work contexts" to refer to two levels of analysis: occupations and organizations. Occupations demarcate socially understood jobs, and structure opportunities and rewards, while organizations provide the context in which workers do their jobs. There have been recent turns in the sociology of work and organizational behavior to reintegrate occupations and organizations (Anteby et al. 2016, Tomaskovic-Devey 2014), one consequence of which is to draw attention the difficulty of disentangling them. This is both because many outcomes, including earnings, are jointly determined (Mouw and Kalleberg 2010), and because there is covariance of occupation and organizational form. Within large organizations, jobs are often clustered by occupation into their own delineated teams, with their own cultures (Kirkman and Shapiro 2001), while many kinds of organization, such as hospitals, are specific to a group of occupations. Occupations thus nest in organizations, which nest in occupations. Organization and occupation are as much complimentary as competing explanations of sociability, with many mechanisms, such as selection, operating in parallel, and mechanisms that take place at one level clustering at the second level, such as schedule-setting, which takes place in organizations, but covaries with occupation.

[Insert Table 1 about here.]

\section{Coordination}

Sociable interactions require that two coworkers are available at the same time. The number of workers in a workplace, the extent to which they are brought into contact, and their schedules all determine if this occurs. Workplaces vary from being solitary to containing many 
employees, with the nature of the work a determinant. Solitary work is easier when tasks require few workers, such as journalism or janitorial work. Equally, there is within-sector variation in firm size. Many jobs can exist either directly in a large firm, or in smaller organizations that are in turn contracted by a larger organization, such as call centers in the service sector.

But even within similar-sized workplaces, organization varies the extent of interactions. Many organizations use teams, increasing the number of coworkers a worker will know (Ezzamel and Willmott 1998). Equally, sociability in the workplace is dependent on an "interaction space" (Kellogg 2009). These are understood by workers and their bosses as appropriate sites of sociability, and having access to such a space may induce workers to socialize more.

Organizations influence sociability by controlling schedules, which determines coordination. Time is limited, and non-essential tasks like socializing should be sensitive to time budgets. But, as Young and Lim (2014) argue, time is also a network good: to socialize, other people have to be free to do so, and that requires them to be on similar schedules (Young and Lim 2014). This, like workplace interactions, is a function of both organizational decisions and job tasks: sales work, for example, needs to be scheduled around the availability of customers. When people work should therefore matter for sociability alongside the length of time they work. Standard schedules make sociability with coworkers easier both in and out of the workplace, as workers' schedules are more likely to align.

\section{Intrinsic Motivations to Socialize}

Access to coworkers is a condition for sociability, but coworkers also need to want to socialize. Variation in general sociability likely has both selection and causal components, while orientation towards socializing with coworkers, specifically, is likely influenced by homophily, the nature of working relationships, workplace culture, and opportunity costs.

Workers may select into both occupations and organizations based on their sociability. Work 
tasks vary in the extent to which they require social interaction, either with customers or with coworkers, with some occupations largely solitary, and many others, such as many blue collar or engineering occupations, inherently requiring teamwork (Hodson 2001, Kozlowski and Bell 2003). In a meta-analysis, Barrick et al find high levels of extroversion to positively correlate with choosing social, enterprising, and artistic occupations (Barrick et al. 2003). At the same time, organizations select workers based on their fit with the social culture of the organization (Rivera 2012), and it is plausible that workers differentially apply to organizations based on the same metric.

Equally, occupations shape their occupants. While jobs for life are increasingly rare (Kalleberg 2009), it is still the case that workers usually stay in an occupation for a long time. Occupations provide workers with a stable set of job tasks, and the content of job tasks can change workers' personalities. Though most previous work on this topic relates task complexity to intellectual curiosity (Spenner 1988), it is plausible that sociable work, over the long term, produces sociable people.

In parallel to the individual workers' propensity to socialize, its relational equivalent should matter: the extent to which workers specifically want to socialize together. First, opportunity costs matter. In the workplace, socializing either displaces solitary breaks or work time. After work, people usually prefer to socialize with friends, but just as work schedules affect coordination between coworkers so they do the same for coordination with friends and family (White and Keith 1990). When workers are on non-standard schedules they will usually find it harder to socialize with friends, and instead may turn to coworkers.

Second, coworkers are more motivated to socialize if they are alike. Research in lab and real-world settings has shown that shared identities, characteristics, and group membership increases social interaction (Bowles 2006, Goette et al. 2006, McPherson et al. 2001). Work itself is one such shared identity, but it varies in nature and intensity.

Both workers and management can deliberately construct shared identities in organizations. 
Organizations in sectors where employees have hard-to-replace skills, such as technology, cultivate "strong" cultures (Kunda 2009). Workers are encouraged to internalize organizational, so that workers will coordinate without overt bureaucratic control. So ubiquitous has this become that more than three-quarters of Fortune 500 CEOs recently listed corporate culture among their top three concerns (Chatman and O'Reilly 2016). In parallel, public sector organizations often cultivate a "public service ethos," grounding workers' identities in an overtly moral framework (Rayner et al. 2011).

Workers can also create shared identities independent of management (Hodson 2001). Workers cultivate solidarity based upon shared experiences (Goffee 1981), and strong social relations (Hodson 2001). But the relationship between social relations and solidarity likely also runs in the opposite direction: if there is a strong shared identity among coworkers, they are more likely socialize. One potentially strong source of solidarity is membership in a labor union. Unions provide a secondary identity, not linked to management, and it is an identity that is likely viewed as less hierarchical than the organization as a whole, and thus less in tension with sociability.

Equally, homophily is likely lower in particularly competitive occupations. Competition inhibit trust and promotes oppositional behavior. While competition is ubiquitous in workplaces, it is much more intense, and more visible to workers in some occupations. This is likely to be the occupations where remuneration is based upon commission, such as real estate brokers, in which workers may conceptualize rewards as zero sum.

\section{Differential Incentives for Sociability}

The above mechanisms operate on a worker's internal orientation towards sociability. But work introduces a particularly strong set of extrinsic motivations, because work provides material resources. The relationship between sociability and instrumental motivations is dependent, first, on the consequences of coworker sociability for a particular job. Some 
organizations and occupations expect sociability, while others do not. Second, in some jobs and workplaces, workers will be sensitive to expectations of sociability, because they have more to gain from meeting expectations, or because they are safe from the consequences of ignoring them. Similarly, workers socialize to build social capital, but social capital is not equally useful in all kinds of jobs.

The extent to which organizations and coworkers expect sociability varies across work contexts. As discussed above, many organizations try to encourage sociability as a component of firm culture. But in the workplace, sociability displaces work time, and so many organizations try to discourage it, by monitoring breaks or productivity (Reich and Bearman 2018). This is common in large workplaces in low wage sales- and service-sector occupations, such as big box stores, where employee turnover is high and job-specific skills relatively low (Kalleberg 2012).

Jobs may or may not come with expectations around sociability, but whether workers match expectations is another matter. First, the relative power of workers in organizations determines if workers can ignore organizational pressure. Workers are more powerful when they are harder to replace, or when they organize to circumscribe managers' power (Hodson 1997). Union-negotiated contracts, for example, limit managers ability to discipline workers. In the workplace, unionization should make it easier for coworkers to socialize on the job without management reprisal. Outside of work, where the alternative to sociability with a coworker is not work but often some other preferable form of leisure activity, unionization has the opposite effect, making it easier for workers to safely ignore organizational demands to socialize.

Second, occupations create different incentives. By doing well at work, workers can gain greater rewards, and increased status, but progression is not available in all occupations. In high-status work, such as professional occupations, there are clear career paths, with expectations that mobility will be accompanied by benefits, and this provides strong incentives 
for high-status workers to follow expectations around sociability. This kind of career structure is rarer in low status work (Kalleberg 2012).

Equally, social capital is consequential for workplace outcomes (see below), but its utility may vary across jobs. As Weber argued, rational-legal authority, which characterizes modern bureaucratic organizations, attempts to eliminate personal ties as sources of claims on functionaries (Weber 2009). But some parts of the economy have remained non-bureaucratic, and there social ties are more important (Mears 2015), while even within putatively rational-legal organizations, there is variation in levels of bureaucratization. Governmental organizations are usually more fully bureaucratized than private ones, while formal rules that limit managerial discretion are an explicit goal of most labor unions.

\section{Cultures of Sociability and their Consequences}

Workplace incentives are more likely to influence coworker sociability if it is consequential. Research suggests that social relationships contribute to workplace outcomes (Castilla 2005, Fernandez et al. 2000, Podolny and Baron 1997, Shwed and Kalev 2014), and socializing is an antecedent to this. Equally, the ways in which work contexts pattern sociability, laid out in the previous section, may make sociability consequential for workers, if these differing aggregate patterns in sociability are accompanied by sociability norms and expectations.

\section{Social Relationships}

Sociability, over time, creates social relationships between coworkers. These relationships can be consequential for workplace outcomes. They provide actors access to resources that they would lack otherwise, and which constitute social capital (Burt 2000, Lin 2002). For

hiring, personal contacts with existing workers in a workplace are an important way in which workers find out about new jobs, and the social status of workers' contacts, the nature of their 
ties to those contacts, and the extent of their social network are all associated with hiring (Fernandez and Weinberg 1997, Granovetter 1973, Lin 1999). In the workplace, informal ties are associated with faster human capital accrual (Morrison 2012), increased creativity (Fleming et al. 2007), better evaluations (Shwed and Kalev 2014), and intrafirm job mobility (Burt 1992, Podolny and Baron 1997).

But informal relationships can also be deleterious to workplace outcomes, for many of the same reasons that work makes sociability between coworkers fraught. Friendships at work suffer from role ambiguity, and while work relationships are predicated on instrumentality, friendships rely on its absence. These roles may come into conflict, with friends having to choose friendship or organizational priorities (Pillemer and Rothbard 2018). Friendships, while they can provide support, may also be distracting, and thus impact productivity.

By focusing on the sociable interaction, instead of the long term relationship, it is possible to examine the circumstances in which contradictory theories about the positive or deleterious influence of social relations between coworkers on workplace outcomes apply. In particular, where sociability takes place should matter a great deal. A workplace setting makes role ambiguity more salient, and it is only at work that sociability can be deleterious for productivity. Outside of the workplace, however, sociability is less affected by these tensions. In addition, because it less circumscribed by the spatial organization of the workplace in which workers are usually placed together in teams of similar workers, coworker sociability outside of work is more likely to expose coworkers to a broader network, which in turn is more useful for the cultivation of social capital (Burt 1992, Granovetter 1973).

\section{Social Fit}

Workers see improved outcomes when they match the norms and expectations of their jobs. The literature on cultural fit between workers and job has for the most part focused on cognition: whether or not employees express values congruent with those of their organization. 
Researchers have recently turned their attention to behavior (for a review of this literature see Mobasseri et al. 2019). Srivastava et al. (2018) finds that worker adoption of the linguistic style of coworkers predicts tenure and promotion, while Rivera (2012) argues that recruiters at elite firms both use worker-organization lifestyle fit as a formal evaluation metric, and more positively evaluate candidates with whom they share lifestyles.

Despite this behavioral turn, past research has not examined sociability as a dimension of behavioral fit. Yet, as we have seen, sociability is an important component of the kinds of cultures managers cultivate in organizations (Chatman and O'Reilly 2016, Fleming and Spicer 2004, Kunda 2009). Indeed, sociability is a stated motivation of recruiters when they explain their emphasis on lifestyle (Rivera 2012). According to one management consultant, "[i]t's way more fun if the people around you are your friends. So, when I'm interviewing, I look for people... I'd want to get to know and want to spend time with, even outside of work ... people I can be buddies with." (Rivera 2012).

Employees at elite firms seek new hires with whom they want to socialize, but in the low information situation of the hiring process, use lifestyle as a proxy. According to Rivera (2012), workers at these firms prioritize sociability because coworkers already make up the majority of their social networks. While Rivera's case is the hiring process, the motivations of her interviewees suggest that sociability continues to be an important aspect of cultural fit thereafter, as workers at elite firms are expected to cultivate work colleagues socially.

Sociability thus may be consequential as a way for workers to cultivate social capital. It also may be consequential if, first, workplaces develop norms governing sociability, and, second, workers benefit when their behaviors match the norms. While we know a great deal about the kinds of relationships from which workers benefit, we know far less about how and where coworkers go about cultivating those relationships, and about sociability as a dimension of cultural fit. Nor we do we know very much about what sociability contexts for American workers look like: previous work has neither established in which jobs workers socialize with 
their coworkers, nor the mechanisms driving these patterns, nor the analytical level at which they occur. Finally, we know little about how American workers experience socializing with coworkers: qualitative accounts suggest that it can be fraught, but is it less pleasant or meaningful than sociable interactions when other kinds of social relationships are involved? It is to addressing these gaps that the paper now turns.

\section{Data and Time Use Measures}

The analyses proceed in three parts. The first section establishes that sociability between coworkers differs from sociability between friends both in affect and revealed preference. The second section examines the work determinants of sociability both in the workplace and outside of work. The third section examines the influence of sociability on wages, and how that relationship is conditional on both workplace culture of sociability and the setting of social interactions.

\section{Time Diaries and Time Use Measures}

The American Time Use Survey (ATUS) is a time diary survey, which allows for the construction of time use measures of coworker sociability (Hofferth et al. 2018). ATUS prompts respondents to record activities for 24 hours prior to $4 \mathrm{AM}$ on the day of the survey. Answers are are coded into activity categories at the Bureau of Labor Statistics, and nested in activity groupings. Respondents are asked to list the start- and end-time and location of activities and who was present. Table 2 provides an example diary for one respondent.

The measures of sociability combine activity, duration, location, and copresence variables. The analyses use three key measures of sociability: socializing with friends, with coworkers in the workplace, and with workers outside the workplace. These sum the minutes spent in 
appropriate activities-copresence-location combinations (when used as independent variables in the regression analyses, these variables are dichotomized).

Socializing with friends uses all activities from the socializing and leisure broad activity grouping, along with eating and drinking with friends, in any location. For the respondent in Table 2, four activities meet these criteria: three instances of socializing and communicating, and attending a party, with a duration of 335 minutes. Socializing with coworkers outside of work uses the same activities, but limits location to outside of work, and in our example no activities meet these criteria.

Socializing with coworkers in the workplace combines all activities from the socializing and leisure categories, but omits eating and drinking, because it is not possible to distinguish solitary eating in a workplace canteen from social eating. When a respondent eats with a coworker outside of the workplace, in contrast, it is likely that they chose to eat with a coworker. In our example, one activity meets these criteria: watching $\mathrm{TV} / \mathrm{movies}$ in the workplace, for fifteen minutes. Figure 1 shows the contribution of activity groupings to the measures. For coworker sociability at work, most time is spent on activities categorized as first, relaxing and leisure, and second, socializing. $60 \%$ of coworker sociability outside of work is eating and drinking, which is unsurprising given that leaving work is socially sanctioned for meals but not generally otherwise, while socializing and communicating and attending or hosting social events each make up 10-15\% of the measure. Table 3 reports descriptives for all variables.

[Insert Figure 1 about here.]

These measures do not perfectly capture sociability, for three reasons. First, because ATUS is a 24 hour diary respondents spending no time in sociable activities is common. This is accurate, but means that many respondents are categorized as not sociable at all, when over the course of a week they likely do socialize.

Second defining activity partners is inexact. The only activity partner category available 
for non-work activities across all years of the survey combines coworkers and clients, but, ideally, the measure would exclude socializing with clients. A supplementary analysis excludes client-focused occupations, defined as occupations for which more than $20 \%$ of workers record client or customer presence for a work activities, and results are substantively similar (Appendix A).

Moreover, it is possible that occasionally respondents are socializing with coworkers who are not categorized as such. This could be particularly problematic if respondents are classifying their coworkers as friends, as the measure would exclude the most enduring relationships. Outside of work, it is not possible to identify these cases, but for sociability in the workplace I infer that activity partners categorized as friends are also coworkers, so these cases are used as a sensitivity check. Relatively few respondents' categorize workplace sociability partners as friends (186 vs. 3,514). Repeating the analyses including these cases does not change the results (Appendix B).

Third, classifying activities as relevant to sociability or not is inexact. The social psychological literature on sociability emphasizes that social interactions motivated by a desire to socialize are voluntaristic and usually pleasant (Baumeister and Leary 1995, Downie et al. 2008, Nezlek et al. 2002), traits shared with leisure activities. But the measure likely misses some sociable behaviors not explicitly categorized as socializing or leisure by ATUS. Taking a class with a coworker, or sharing a lift to work, for example, may, in some cases, be sociable. In other cases, however, respondents may think of these activities as work, service, or chores. Given, however, the importance of voluntarism and interaction quality, using a too narrow measure seems preferable to a too broad one.

[Insert Table 2 about here.] 


\section{Other Data}

ATUS is drawn from the CPS, allowing researchers to draw on the contextual data collected previously. But this leads to attrition. Respondents are surveyed two to five months after CPS, and the response rate is around $50 \%$. Response rates do not vary substantially with how busy respondents are, but they vary with aspects of SES (Abraham et al. 2006). To correct this, ATUS provides weights constructed using race, sex, education, presence of children, age, administration day, and incentives to participate. Abraham et al. (2006) find that weighting by a broader set of characteristics, including income, housing tenure, household composition, marriage, the presence of a telephone, and geography, and changes time use estimates very little.

In 2010, 2012, and 2013, ATUS included a wellbeing module, which I use to examine the relationship between sociability and affect. The wellbeing module is designed to supplement global measures of wellbeing by collecting data on variation in affect during daily activities

(Stone and Mackie 2013). Using the day reconstruction method (Kahneman et al. 2004), the module randomly selects five activities and asks respondents to describe their feelings during each. Respondents rate their feelings from 0 to 6 , corresponding to absence of the feeling to a very strong feeling. The sample of sociable activities in this module is small (see Figure 2), and so analyses using the wellbeing module are bivariate and descriptive.

The analyses presented here pool ATUS samples from 2003 to 2016, but exclude several categories of respondents. Models include employed respondents of prime working age (25-55) in full time work, to reduce variance in underlying labor force attachment. Because ATUS does not record earnings for self-employed individuals, they are excluded. Union status is only recorded in the eighth month of the CPS panel, so analyses exclude respondents who changed jobs between CPS and ATUS. Models of sociability in the workplace exclude days not working. This gives samples of 25,602 and 41,848 for sociability in the workplace and outside of work. 
To supplement the work measures recorded in ATUS, the analyses use occupational measures from ONet and CPS, the latter constructed with data from 2003 to 2016. ONet uses workplace surveys to measure occupation-level work characteristics on a comprehensive range of topics (Hadden et al. 2004). The ONet measures used have been collected since 2001 using occupational surveys, and which ask respondents in a given occupation to rate the importance of a work-task or -style. ONet is often used, as here, in combination with person-level data, to measure occupational exposures and characteristics (Cifuentes et al. 2010).

[Insert Table 3 about here.]

\section{Analysis and Results}

\section{Sociability Among Coworkers and Friends}

In its ideal type, sociability is non-instrumental and volitional (Simmel and Hughes 1949). Work, which is often insrumental and coercive, is thus a potentially challenging context for sociability. In a number of case studies, workers report struggling with the role ambiguity inherent in socializing with coworkers (Coser et al. 1982, Hodson 2001, Ingram and Zou 2008, Kunda 2009).

Figure 2 uses the wellbeing module of the American Time Use Survey (ATUS) to examine reported happiness during and meaningfulness of sociability across four combinations of activity, location, and partner: sociability between coworkers in the workplace and outside of work respectively, sociability between friends, and, as a baseline, work. Figure 3 turns from affect to revealed preferences, and plots the proportion of workers who socialize with coworkers in the workplace and outside of work, and with friends, and the mean time spent socializing among those who socialize.

[Insert Figure 2 about here.] 
Figure 2 presents strong evidence that people find socializing with coworkers challenging. As expected, people generally like social activities: happiness is higher for all kinds of sociability than for work. But people are happier socializing with friends than socializing with coworkers in any setting, and find interactions with friends more meaningful. This suggests that affectual differences in socializing with friends and coworkers are not only the result of setting, but indicative of the quality of interaction. Location does, however, matter: in the workplace, people are less happy while socializing than outside of work.

[Insert Figure 3 about here.]

Revealed preferences also support this conclusion (Figure 3). While a similar proportion of workers socialize with coworkers at work as socialize with friends, outside of work, where workers have more agency over with whom they choose to associate, half as many workers socialize with coworkers as friends. Among those who socialize, the relative time spent with friends and coworkers suggests people prefer socializing with friends. The mean time spent socializing with coworkers outside the workplace is about an hour, less than half of the mean time spent socializing with friends.

\section{The Work Determinants of Sociability}

The relationship between between sociability and affect suggests that sociability between coworkers is distinct from other sociability. If coworker sociability is conceptualized by workers as distinctively work-related, and if it is also distinctively patterned by workplace location, then it is likely that coworker sociability is also patterned by work contexts.

[Insert Figure 4 about here.]

Figure 4 suggests that this is the case. It plots the occupational class distribution of sociability between coworkers in the workplace and outside of work, and sociability between

friends. Sociability between coworkers across occupational classes deviates from the mean 
to a far greater extent than sociability between friends. But, coworker sociability in the workplace and outside of it almost mirror each other: in the workplace, sociability is most frequent in traditional blue collar occupations, and lowest in professional and managerial occupations, while outside of work the reverse is true. This section examines occupational and organizational differences in rates of coworker sociability in and outside of the workplace. It examines the organizational and occupational characteristics that influence coworker sociability.

\section{Work Characteristics}

Table 1 lays out the coordination, intrinsic, and incentive-related mechanisms linking work contexts to sociability. Using ATUS, it is possible to explore many of these, including schedules, selection, personality-task alignment, homophily, and incentives. Tables 4 and 5 report parallel sets of models of rates of sociability in and out of the workplace, and which regress sociability on organizational and occupational characteristics.

The models are quasipoisson regressions, and coefficients represent the percent change in the dependent variable associated with a one unit change in the predictor. ${ }^{1}$ The dependent variables are counts of minutes and so all values are non-negative integers. They are also overdispersed: $10.5 \%$ and $4.5 \%$ of respondents socialize with coworkers. This precludes using standard Poisson regression, which assumes that the mean of the distribution is equal to its variance. Quasipoisson relaxes this assumption by estimating the dispersion parameter from the data (Hoef and Boveng 2007). Alternative approaches include negative binomial regression, which is sensitive to outliers (Aeberhard et al. 2014), and log-transforming the dependent variable. Log-transforming requires adding an arbitrary value to the dependent variable to remove zeros, and thus is also not ideal. However, log-transformation produces extremely similar results (Appendix C).

\footnotetext{
${ }^{1}$ This is the incident rate ratio minus 1 , and multiplied by one hundred.
} 
Model 1 regresses coworker sociability organizational characteristics, related to coordination, worker power, social capital, and homophily. Union status may influence sociability via worker power or homophily, while employer type (private/governmental/nonprofit) relates to social capital utility and homophily. Working a nonstandard schedule, defined here as earlier than $6 \mathrm{AM}$ or later than 7PM on a weekday, or on a weekend, is important for schedule alignment, and hours worked for time budgets, and both of these measures also relate to opportunity costs. I control for time spent taking solitary work breaks, to ensure that sociability is not confounded by general non-work time spent in the workplace. I include detailed occupation fixed effects, which requires estimating this model separately from Model 2, which includes covariates measured at the level of occupation.

I include two key non-work controls. The first sums time spent doing any form of care work or housework. Care work limits opportunities to socialize, but also shapes work opportunities (Gough and Noonan 2013). The second is a dummy indicator of spending any time socializing with friends. Whether or not a respondent socializes with friends indicates a general propensity to socialize, as well as alternative opportunities to socialize. Also included are year and day of the week (not shown), gender, hispanicity, age and its quadratic. It includes race (Black/White/Other), and schooling (less than high school degree, GED, high school degree, some college, college degree), marital status, and a categorical measure of how many children the respondent has $(0,1,2,3+)$. The non-workplace models also include a dummy variable indicating if the diary fell on a workday (not shown).

Model 2 adds occupational measures that relate to homophily, task-related conditioning, and incentives. The social context of work tasks may shape propensities to socialize, and so the model includes an ONet measure of the importance of social orientation to an occupation's work style, which ONet defines as being personally connected to others on the job. Jobs that require coworker interactions, specifically, increase the pool of coworkers workers know, and so may increase sociability. The model therefore includes an ONet measure of the importance 
of teamwork in an occupation. Conversely, intense competition between coworkers may reduce homophily and solidarity between coworkers, and so the model includes an ONet measure of occupational competitiveness. All these are standardized.

Finally, model 2 also adds two measures of status and material rewards. Higher status jobs have lower turnover and more defined career structures than low status jobs, which in turn increases the incentives to be responsive to organizational demands and norms around sociability. The model therefore includes measures of logged weekly earnings and occupational status, operationalized as the proportion of an occupation with a college degree (Hauser and Warren 1997). Outside of work, socializing can cost money. To separate the influence of resources from the incentive-related component of earnings, the non-workplace model also includes family income. ATUS records family income in brackets and top codes, so the model includes family income categorically (not shown). As a control, the model includes dummies for detailed industry.

[Insert Tables 4 and 5 about here.]

Organizational characteristics are associated with coworker sociability in complex ways, as Tables 4 and 5 show. There is a strong association between union status and socializing with coworkers in the workplace. Union status may influence sociability via the mechanisms of worker power or homophily, with the fact that the association is confined to workplace sociability suggesting the former. Stronger evidence for the importance of homophily is provided by the high rates of sociability outside of work among government workers, who share a public service ethos. Equally, this suggests that workers aren't differentially motivated to socialize based upon the relevance of social capital to their jobs.

Working a nonstandard schedule is associated with increased sociability in the workplace, and decreased sociability outside of work. Outside of work, non-standard schedules makes coordinating more difficult. And schedule misalignment between workers on non-standard schedules and their friends and families may drive them to socialize with coworkers while 
at work. Hours worked is negatively associated with sociability in the workplace. If the associations were driven by opportunity costs or time budgets they would run in the opposite direction. One plausible explanation is that hours worked proxies organizational commitment.

Occupational covariates provide further evidence that homophilous coworkers socialize at higher rates: in the workplace, coworker sociability declines with occupational competitiveness. Model 2 also suggests that incentive structures matter. In the workplace, status and earnings negatively predict sociability, while outside of work earnings positively predict sociability. This is consistent with high-status workers responding to incentives not to slack off in the workplace, but to either cultivate social capital or conform to sociable norms outside of work. The models provide little evidence that work-based coworker interactions are related to sociability, while sociable work tasks seem to suppress, rather than encourage sociability.

Tables 4 and 5 suggest that coworker sociability is highly responsive to work contexts. The differences in patterns of sociability across work contexts are the response of coworkers to work-based differences in incentives, power arrangements, and group identities. The models

provide evidence for the influence of homophily at both the organizational and occupational level, with governmental work, occupational competition, and union status, all promoting coworker homophily and sociability. Worker responsiveness to institutional demands and norms is much stronger among higher status workers for whom there are clear pathways of career progression, and they are weaker for workers insulated from organizational discipline by union membership.

\section{Behavioral Fit and Occupational Cultures}

Occupations place workers in contexts of sociability. As Figure 4 shows, the average production worker's context is one in which workers socialize in the workplace at around four times the rate of the average manager. When behaviors are accompanied by norms that code those same behaviors as appropriate or otherwise, contexts become cultures. The mechanisms 
linking work to sociability suggest that work may create distinctive cultures of sociability: work influences sociability via cognition. Coworkers socialize at greater rates when their shared identity as coworkers is strong and positive, for example in unionized workplaces, or in occupations with low internal competition. Group identities and norms are reinforcing, because shared norms create a further point of in-group similarity, which in turn encourages association and identification.

Cultures often reward compliance and sanction deviance. Workers who fit, culturally, stay in their jobs longer, are more likely to be promoted, and have higher levels of job satisfaction than those who do not (Chatman 1991, Srivastava et al. 2018). Previous research, however, has not examined the material rewards for sociability, either directly or in tandem with work cultures of sociability.

Most previous studies on work cultures focus on organizations, but occupations are also an appropriate level of analysis. Ethnographic researchers have found that occupations have distinct cultures, and that these come with norms and expectations around sociability (Van Maanen and Barley 1982). Furthermore, processes which take place in workplaces and organizations often still cluster by occupation (Kirkman and Shapiro 2001, Mouw and Kalleberg 2010).

To check that occupations explain a substantial amount of variance in sociability, Appendix D presents a series of decompositions of variance of sociability by individual characteritistics, occupation, and organization/industry, using the covariates in Tables 4 and 5, and adding detailed industry. ${ }^{2}$ Models containing detailed occupation alone explain $78 \%$ and $54 \%$ of the total variation explained in a saturated model of workplace and outside of work sociability, respectively. In comparison, individual characteristics explain only $24 \%$ and $31 \%$. Occupation also explains far more marginal variation ${ }^{3}$ in sociability than individual characteristics.

\footnotetext{
${ }^{2}$ To enable decomposition of variance, the models presented in Appendix D are linear regressions with a logged dependent variable. The substantive results presented in Tables 4 and 5 using quasipoisson are extremely similar when estimated using linear regression (see Appendix C).

${ }^{3}$ That is, the portion the saturated variance left unexplained by models containing all variables except
} 
Tables 6 and 7 examine the relationship between earnings, workers' sociability in the workplace and outside of work, and cultures of sociability, by regressing logged earnings on individual and occupational sociability in and outside of the workplace, and their interaction. As before, there are parallel sets of models for the two sociability contexts. Model 1 regresses earnings on respondent's sociability and the same individual controls as for Model 4.1, above. Coworker sociability here is dichotomized, because the continuous measure is overdispersed. These models also include a measure of family income (not shown).

Model 2 adds the same work measures included in 4.2 and 4.3 above, except for detailed occupation and industry, and adds a measure of broad occupational class. Models 3 and 4 are identical to Models 1 and 2, but add measures of occupational sociability and interact them with respondent-level coworker sociability. Occupational sociability is the proportion of workers in an occupation who report socializing with a coworker in ATUS. These are linear models, but because ATUS top codes weekly earnings at $\$ 2884$, Appendix E replicates the results using Tobit regressions.

[Insert Tables 6 and 7 about here.]

There is a meaningful relationship between individual-level sociability and earnings, but it depends on location. In the workplace, where excessive sociability is often perceived as slacking off, sociability is negatively associated with earnings, controlling for individual characteristics. The association is reduced by about half by including work controls, although it remains significant (Model 2). Outside of the workplace, where sociability does not hold the same stigma and so where the instrumental benefits of sociability as a way to cultivate social capital are greatest, the relationship is positive, and not meaningfully affected by work controls.

[Insert Figure 5 about here.]

For sociability in the workplace, but not outside of work, the association between earnings occupation. 
and sociability varies by occupational sociability levels, and there is a substantial penalty for sociable workers in unsociable occupations, which declines as the sociability of the occupation increases (Figure 5). Unsociable workers earn $\$ 30$ per week ( $\$ 1560$ per year) more than their sociable counterparts in unsociable occupations. In occupations in which $30 \%$ of workers socialize with each other, however, earnings for sociable and antisocial workers are indistinguishable. This interaction is robust to controlling for work characteristics, including competition, social work tasks, levels of teamwork, and occupational status (Model 4). Both models 3 and 4 also control for sociability with friends. The interaction is thus not explained by general sociability, but specifically by socializing with coworkers.

The interaction between individual and occupational sociability suggest that sociability context is accompanied by a culture of sociability, and that workers benefit from conforming to the dominant culture of sociability in their job. These norms hold for the workplace, where there are strong general expectations surrounding worker conduct, but not outside of work, where such expectations are weaker.

\section{Discussion}

This study finds that sociability between coworkers is a distinct phenomenon, which feels different and has different consequences to general sociability. Coworker sociability is patterned by work, with sociability explained by both homophily and differential incentives. Outside of work, workers who socialize earn higher wages than those who do not, which suggests that sociability is a strategy for social capital accrual. In the workplace, patterns of sociability create distinct cultures of sociability with concomitant expectations for workers' social behavior. Workers who socialize at work receive lower wages than those who do not, but as occupational sociability increases, this gap declines and then disappears. This study contributes to the sociology of sociability, work, organizational behavior, and cultural 
matching.

\section{Sociability and Social Fit}

This is the first study to examine sociability as a dimension of worker-job fit. Previous work has shown that value congruence between a worker and their job or organization leads to improved workplace outcomes on multiple dimensions (Elfenbein and O’Reilly 2007, Mobasseri et al. 2019), and more recently researchers have turned to assessing the behavioral aspects of cultural fit, and have found evidence for the importance of lifestyle for hiring (Rivera 2012), and of language for tenure and promotion (Srivastava et al. 2018). Identifying a new domain of behavior - informal social interactions - and a new outcome - earnings - in this nascent literature is itself an important finding, and one that could be followed up with further research on both alternative workplace outcomes, and organization-worker matching.

This finding suggests a distinction should be made in the cultural fit and matching literatures between behaviors that do not presume coworker or workplace interactions, and those that do. Social fit or matching, which does require interaction, includes both coworker sociability and the linguistic enculturation practices identified by Srivastava et al. (2018). Dimensions of cultural fit that to do not presume social interaction include the lifestyle behaviors identified by Rivera (2012).

Such a distinction illuminates when different elements of cultural fit are important. Rivera's interviewees give expectations of future sociability as their motivation for prioritizing lifestyle in hiring decisions. That is, because they cannot test directly if they will enjoy socializing with potential hires, they use lifestyle as a proxy measure. This suggests that lifestyle fit should be important for hiring, but in the workplace social fit will be more consequential. This distinction also emphasizes the way in which social and lifestyle fit may be related. While previous work considers the relationship between cultural fit and social embededness within organizations (Goldberg et al. 2016), if lifestyle proxies presume sociability, then the 
importance of lifestyle should be heterogeneous by the culture of sociability in, and thus the density of interactions in, a job or organization.

\section{Sociability and Social Interaction}

Examining sociability between coworkers also has implications for sociability itself, and informal social interactions more broadly. First, it draws our attention back to semi-habitual interactions. Recent sociology of sociability has mostly focused on irregular events (Wynn 2016), such as parties (Goffman 2019) or weddings (Sniezek 2005). These, while disproportionately important to people's lives, are not typical of sociability, which mostly occurs between people who see each other regularly, know each other, and have for a long time (Baumeister and Leary 1995), yet we know little about the structural determinants of more quotidian social interactions, particularly in relation to work.

Focusing on quotidian interactions also suggests a synthesis between the two most prominent theoretical conceptions of sociability in sociology. Simmel theorized sociability to be a social relation that requires separation from the roles, including status roles, and motivations of everyday life. Goffman, in contrast, saw sociability itself as thoroughly imbued with status competition. This is certainly the case (Goffman 2019), but Simmel emphasizes not the internal dynamics of sociability, but the interaction between sociability and external roles and motives. The substantial differences in the affective valence of sociability between coworkers and friends suggests that Simmel was broadly correct: when there is more potential for role ambiguity and instrumental motivations are stronger, sociability is considerably more problematic for workers.

Quasi-habitual sociability is not ignored by scholars, but the interaction itself is usually abstracted away, because it is usually studied in the networks paradigm, and conceptualized as a relation, or tie, and thus a state rather than a process. A consequence of this conceptual move is that the context of the interaction is usually ignored. This study suggests that 
this is an important gap in the literature. Sociability simply in a different location - in the workplace or outside of it - is associated with different emotional valence, work determinants, and consequences for earnings. Similarly, there are differing earning returns to sociability associated with more or less sociable occupational cultures. Future research should consider the ways in which work contexts influence social network formation, and the rewards associated with workplace social networks.

\section{Work and Sociability}

Coworker sociability is affectually distinct from socializing with friends, and is strongly influenced by work contexts. The sociology of work has recently taken a relational turn, with researchers examining the ways in which workplace and organizational interactions can structure individual outcomes and workplace inequalities (Mears 2015, Tomaskovic-Devey 2014, Vallas and Cummins 2014). But thus far work in this tradition has either focused on relations between workers and managers (Hodson et al. 2006, Roscigno et al. 2009), or inequality-generating mechanisms of social closure (Tomaskovic-Devey 2014). Little work has considered informal horizontal relations (for an exception see Roscigno et al. (2018)). Yet we know that informal social relations are important in their own right, and contribute to workplace outcomes (Castilla 2005, Fernandez et al. 2000, Podolny and Baron 1997, Shwed and Kalev 2014)

Moreover, sociability may be an important mechanism for and modifier of the generation of labor force inequalities. Prior research shows that differential social capital is a source of labor market inequality (Lin 2000). The substantial differences in propensity to socialize by work contexts suggests that the dynamics of social capital accrual may function differently in different kinds of work. In highly sociable workplaces, workers have many more opportunities to cultivate useful relationships than they would in less sociable workplaces. It may therefore be the case that the relationship between social capital and inequality varies by occupation 
or organization.

At the same time, sociability may contribute directly to gender inequalities in workplace outcomes. First, as it shown above, women, on average, socialize less with their coworkers than men, even controlling for time spent doing care work, which itself both limits sociability and is disproportionately undertaken by women (Gough and Noonan 2013). Insofar as socializing with workers is useful, this will disadvantage women.

But even when women socialize with coworkers at the same rate as men, it is possible that women do not accrue the same benefits from that sociability as men. The analyses above show the importance of homophily for sociability. In workplaces in which either the overall workforce or employees in positions of authority are disproportionately male, socializing may not translate into the same kinds of instrumentally beneficial relationships for women as for men. Future research should thus consider the role sociability plays in producing unequal workplace outcomes by gender.

\section{References}

Abraham KG, Maitland A, Bianchi SM (2006) Nonresponse in the American Time Use Survey: Who is Missing from the Data and How Much does it Matter? International Journal of Public Opinion Quarterly 70(5):676-703.

Aeberhard WH, Cantoni E, Heritier S (2014) Robust inference in the negative binomial regression model with an application to falls data. Biometrics 70(4):920-931.

Anteby M, Chan CK, DiBenigno J (2016) Three Lenses on Occupations and Professions in Organizations: Becoming, Doing, and Relating. The Academy of Management Annals 10(1):183-244.

Baillien E, Neyens I, De Witte H (2008) Organizational, team related and job related risk 
factors for workplace bullying, violence and sexual harassment in the workplace: A qualitative study. International Journal of Organisational Behaviour 13(2):132-146.

Barrick MR, Mount MK, Gupta R (2003) Meta-Analysis of the Relationship Between the Five-Factor Model of Personality and Holland's Occupational Types. Personnel Psychology $56(1): 45-74$.

Baumeister RF, Leary MR (1995) The Need to Belong: Desire for Interpersonal Attachments as a Fundamental Human Motivation. Psychological bulletin 117(3):497.

Berman EM, West JP, Richter MN (2002) Workplace Relations: Friendship Patterns and Consequences (According to Managers). Public Administration Review 62(2):217-230.

Bowles S (2006) Group Competition, Reproductive Leveling, and the Evolution of Human Altruism. Science 314(5805):1569-1572.

Burawoy M (1982) Manufacturing Consent: Changes in the Labor Process under Monopoly Capitalism (University of Chicago Press, Chicago, IL).

Burt RS (1992) Structural Holes: The Social Structure of Competition. (Harvard University Press, Cambridge, MA).

Burt RS (2000) The Network Structure of Social Capital. Research in organizational behavior 22:345-423.

Carnegie D (1933) How to Win Friends and Influence People (Simon \& Schuster, New York, NY).

Castilla EJJ (2005) Social Networks and Employee Performance in a Call Center. American Journal of Sociology 110(5):1243-1283.

Chandler GN, Keller C, Lyon DW (2000) Unraveling the determinants and consequences of an innovation-supportive organizational culture. Entrepreneurship Theory and Practice 25(1):59-76. 
Chatman JA (1991) Matching People and Organizations: Selection and Socialization in Public Accounting Firms. Administrative Science Quarterly 36(3):459-484.

Chatman JA, O’Reilly CA (2016) Paradigm lost: Reinvigorating the study of organizational culture. Research in Organizational Behavior 36:199-224.

Cifuentes M, Boyer J, Lombardi D, Punnett L (2010) Use of O NET as a Job Exposure Matrix. American Journal of Industrial Medicine 53:898-932.

Coser LA, Kadushin C, Powell WW (1982) Books: The Culture and Commerce of Publishing (Basic Books New York).

Downie M, Mageau GA, Koestner R (2008) What Makes for a Pleasant Social Interaction? Motivational Dynamics of Interpersonal Relations. The Journal of Social Psychology 148(5):523-534.

Elfenbein HA, O'Reilly CA (2007) Fitting In: The Effects of Relational Demography and Person-Culture Fit on Group Process and Performance. Group \& Organization Management $32(1): 109-142$.

Ezzamel M, Willmott H (1998) Accounting for Teamwork: A Critical Study of Group-Based Systems of Organizational Control. Administrative Science Quarterly 43(2):358.

Fernandez RM, Castilla EJ, Moore P (2000) Social Capital at Work: Networks and Employment at a Phone Center. American Journal of Sociology 105(5):1288-1356.

Fernandez RM, Weinberg N (1997) Sifting and Sorting: Personal Contacts and Hiring in a Retail Bank. American Sociological Review 62(6):883.

Ferrazzi K, Raz T (2005) Never Eat Alone: And Other Secrets to Success, One Relationship at a Time (Currency Doubleday, New York, NY).

Fischer CS (1982) What do we Mean by "Friend"? An Inductive Study. Social Networks $3(4): 287-306$. 
Fleming L, Mingo S, Chen D (2007) Collaborative Brokerage, Generative Creativity, and Creative Success. Administrative Science Quarterly 52(3):443-475.

Fleming P, Spicer A (2004) "You Can Checkout Anytime, but You Can Never Leave": Spatial Boundaries in a High Commitment Organization. Human Relations 57(1):75-94.

Goette L, Huffman D, Meier S (2006) The Impact of Group Membership on Cooperation and Norm Enforcement: Evidence using Random Assignment to Real Social Groups. American Economic Review. 212-216.

Goffee R (1981) Incorporation and Conflict: A Case Study of Subcontracting in the Coal Industry. The Sociological Review 29(3):475-497.

Goffman A (2019) Go to More Parties? Social Occasions as Home to Unexpected Turning Points in Life Trajectories. Social Psychology Quarterly 82(1):51-74.

Goffman E (1972) Encounters: Two Studies in the Sociology of Interaction (Allen Lane, New York, NY).

Goldberg A, Srivastava SB, Manian VG, Monroe W, Potts C (2016) Fitting in or Standing Out? The Tradeoffs of Structural and Cultural Embeddedness. American Sociological Review 81(6):1190-1222.

Gough M, Noonan M (2013) A Review of the Motherhood Wage Penalty in the United States. Sociology Compass 7(4):328-342.

Granovetter MS (1973) The Strength of Weak Ties. American Jounal of Sociology 78(6):13601380.

Hadden WC, Kravets N, Muntaner C (2004) Descriptive Dimensions of US Occupations with Data from the O*NET. Social Science Research 33(1):64-78.

Halle D (1984) America's Working Man: Work, Home, and Politics among Blue Collar Property Owners (University of Chicago Press, Chicago, IL). 
Hauser R, Warren J (1997) Socioeconomic Indexes for Occupations: A review, Update, and Critique. Sociological Methodology.

Hodson R (1997) Individual Voice on the Shop Floor: The Role of Unions. Social Forces 75(4):1183-1212.

Hodson R (2001) Dignitity at Work (Cambridge Univ Press, Cambridge).

Hodson R, Roscigno VJ, Lopez SH (2006) Chaos and the Abuse of Power. Work and Occupations 33(4):382-416.

Hoef JMV, Boveng PL (2007) Bimodial Regression: How Should we Model Overdispersed Count Data? Ecology 88(11):2766-2772.

Hofferth SL, Flood SM, Sobek M (2018) American Time Use Survey Data Extract Builder: Version 2.7 [dataset].

Ingram P, Zou X (2008) Business friendships. Research in Organizational Behavior 28:167184 .

Jackall R (1978) Workers in a Labyrinth: Jobs and Survival in a Bank Bureaucracy (Allanheld \& Schram, New York, NY).

Kahneman D, Krueger AB, Schkade DA, Schwarz N, Stone AA (2004) A survey method for characterizing daily life experience: The day reconstruction method. Science 306(5702):17761780.

Kalleberg A (2009) Precarious Work, Insecure Workers: Employment Relations in Transition. American sociological review.

Kalleberg A (2012) Good Jobs, Bad Jobs (Russell Sage Foundation, New York, NY).

Kellogg KC (2009) Operating Room: Relational Spaces and Microinstitutional Change in Surgery. American Journal of Sociology 115(3):657-711. 
Kirkman BL, Shapiro DL (2001) The impact of Cultural Values on Job Satisfaction and Organizational Commitment in Self-managing Work Teams: The mediating Role of Employee Resistance. Academy of Management journal 44(3):557-569.

Kozlowski SW, Bell BS (2003) Work Groups and Teams in Organizations. Handbook of psychology. 333-375.

Kunda G (2009) Engineering Culture: Control and Commitment in a High-Tech Corporation (Temple University Press, Philadelphia, PA).

Lin N (1999) Social Networks and Status Attainment. Annual Review of Sociology 25:467-487.

Lin N (2000) Inequality in social capital. Contemporary sociology 29(6):785-795.

Lin N (2002) Social Capital: A Theory of Social Structure and Action (Cambridge university press).

McPherson M, Smith-Lovin L, Brashears ME (2006) Social Isolation in America: Changes in Core Discussion Networks over two Decades. American Sociological Review 71(3):353-375.

McPherson M, Smith-Lovin L, Cook JM (2001) Birds of a Feather: Homophily in Social Networks. Annual Review of Sociology 27(1):415-444.

Mears A (2015) Working for Free in the VIP: Relational Work and the Production of Consent. American Sociological Review 80(6):1099-1122.

Mobasseri S, Goldberg A, Srivastava SB (2019) What is Cultural Fit? From Cognition to Behavior (And Back). The Oxford Handbook of Cognitive Sociology. (Oxford University Press, Oxford), 305-330.

Morrison EIW (2012) Newcomers' Relationships: The Role of Social Network Ties During Socialization. Academy of Management Journal 45(6):1149-1160.

Mouw T, Kalleberg AL (2010) Do Changes in Job Mobility Explain the Growth of Wage Inequality among Men in the United States, 19772005? Social Forces 88(5):2053-2077. 
Nezlek JB (2003) The Motivational and Cognitive Dynamics of Day-to-day Social Life. The social mind: Cognitive and motivational aspects of interpersonal behavior. (Cambridge University Press, Cambridge), 92-111.

Nezlek JB, Richardson DS, Green LR, Schatten-Jones EC (2002) Psychological well-being and day-to-day social interaction among older adults. Personal Relationships 9(1):57-71.

Pillemer J, Rothbard NP (2018) Friends Without Benefits: Understanding the Dark Sides of Workplace Friendship. Academy of Management Review 43(4).

Podolny JM, Baron J (1997) Resources and Relationships: Social Networks and Mobility in the Workplace. American Sociological Review 62(5):673.

Rayner J, Williams HM, Lawton A, Allinson CW (2011) Public Service Ethos: Developing a Generic Measure. Journal of Public Administration Research and Theory 21(1):27-51.

Reich A, Bearman P (2018) Working for Respect: Community and Conflict at Walmart (Columbia University Press, New York, NY).

Richman R (2015) The Culture Blueprint: A Guide to Building the High-performance Workplace (Culture Hackers).

Rivera LA (2012) Hiring as Cultural Matching: The Case of Elite Professional Service Firms. American Sociological Review 77(6):999-1022.

Roscigno VJ, Lopez SH, Hodson R (2009) Supervisory Bullying, Status Inequalities and Organizational Context. Social Forces 87(3):1561-1589.

Roscigno V, Sauer C, Valet P (2018) Rules, Relations, and Work. American Journal of Sociology 123(6):1784-1825.

Shwed U, Kalev A (2014) Are Referrals More Productive or More Likeable? Social Networks and the Evaluation of Merit. American Behavioral Scientist 58(2):288-308.

Simmel G, Hughes EC (1949) The Sociology of Sociability. American Journal of Sociology 
$55(3): 254-261$.

Sniezek T (2005) Is it Our Day or the Bride's Day? The Division of Wedding Labor and its Meaning for Couples. Qualitative Sociology 28(3):215-234.

Spenner KI (1988) Social Stratification, Work, and Personality. Annual Review of Sociology 14(1):69-97.

Srivastava SB, Goldberg A, Manian VG, Potts C (2018) Enculturation Trajectories: Language, Cultural Adaptation, and Individual Outcomes in Organizations. Management Science 64(3):1348-1364.

Stone AA, Mackie C (2013) The Subjective Well-Being Module of the American Time Use Survey: Assessment for Its Continuation (National Academies Press (US), Washington, DC).

Tomaskovic-Devey D (2014) The Relational Generation of Workplace Inequalities. Social Currents 1(1):51-73.

Vallas S, Cummins E (2014) Relational Models of Organizational Inequalities. American Behavioral Scientist 58(2):228-255.

Van Maanen J, Barley SR (1982) Occupational Communities: Culture and Control in Organizations (Alfred P Sloan School Of Management, Cambridge, MA).

Weber M (2009) From Max Weber: Essays in Sociology (Routledge).

White L, Keith B (1990) The Effect of Shift Work on the Quality and Stability of Marital Relations. Journal of Marriage and the Family 52(2):453.

Wynn JR (2016) On the Sociology of Occasions. Sociological Theory 34(3):276-286.

Young C, Lim C (2014) Time as a Network Good: Evidence from Unemployment and the Standard Workweek. Sociological Science 1:10-27. 


\section{Tables}

Table 1: Work Mechanisms of Coworker Sociability

\begin{tabular}{lc} 
Mechanisms & Primary level \\
\hline Coordination: & Organization \\
Workplace size & Both \\
Work interaction & Organization \\
Time budgets & Organization \\
Schedule alignment & \\
Intrinsic Motivation: & Occupation \\
Selection & Occupation \\
Task-related conditioning & Organization \\
Opportunity costs & Both \\
Homophily & \\
Extrinsic Incentives: & Both \\
Cultures of sociability & Organization \\
Worker power & Organization \\
Social capital utility & Occupation \\
Opportunities for advancement & \\
\hline
\end{tabular}




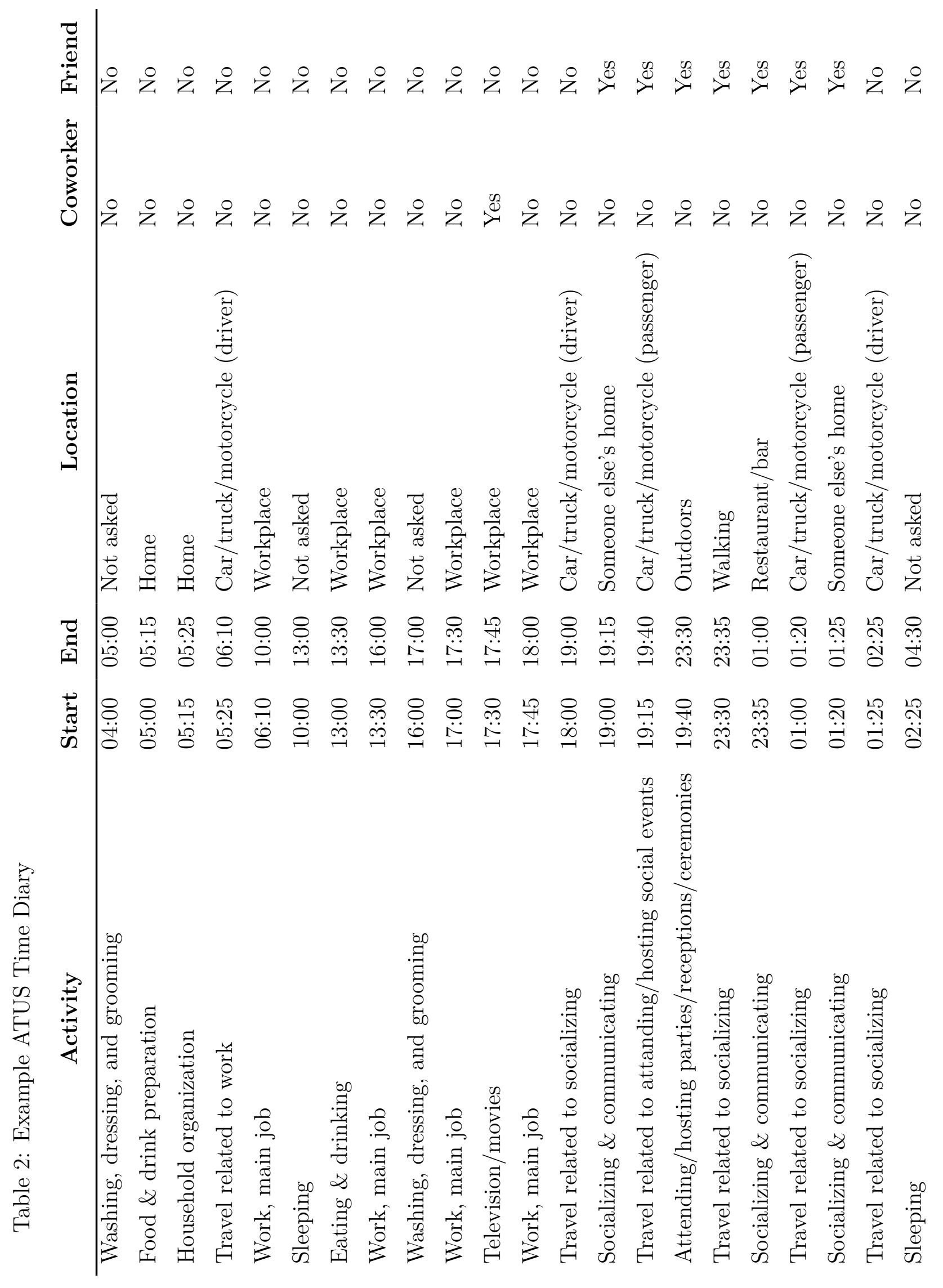


Table 3: Descriptive statistics

\begin{tabular}{|c|c|c|c|}
\hline Variable & Mean/Proportion & SD & Proportion Missing \\
\hline Coworker sociability outside workplace (mins) & 3.02 & 19.4 & 0 \\
\hline Coworker sociability in workplace (mins) & 3.15 & 10.4 & 0 \\
\hline Friend sociality (mins) & 17.7 & 76.5 & 0 \\
\hline Solitary work breaks & 0.14 & 1.69 & 0 \\
\hline Care work (mins) & 61.3 & 115 & 0 \\
\hline Female & 0.42 & & 0 \\
\hline Married & 0.63 & & 0 \\
\hline Hispanic & 0.14 & & 0 \\
\hline Hours worked & 44.6 & 8.17 & 0.03 \\
\hline Weekly earnings (dollars) & 985 & 622 & 0 \\
\hline Team based work (occupational) & 0 & 1 & 0.07 \\
\hline Social work tasks (occupational) & 0 & 1 & 0.07 \\
\hline Competition (occupational) & 0 & 1 & 0.07 \\
\hline Part of labor union & 1.15 & & 0.03 \\
\hline Non-standard work schedule & 0.25 & 0.43 & 0 \\
\hline Race & & & 0 \\
\hline ...White & 0.83 & & 0 \\
\hline ...Asian & 0.05 & & 0 \\
\hline ...Black & 0.1 & & 0 \\
\hline ...Other & 0.02 & & 0 \\
\hline Education & & & 0 \\
\hline$\ldots<\mathrm{HS}$ & 0.07 & & 0 \\
\hline ...HS & 0.24 & & 0 \\
\hline ...GED & 0.02 & & 0 \\
\hline ...Some college & 0.26 & & 0 \\
\hline ...Bachelor's Degree & 0.41 & & 0 \\
\hline Occupational Class & & & 0 \\
\hline ...Professional & 0.32 & & 0 \\
\hline ...Management & 0.13 & & 0 \\
\hline ...Service & 0.11 & & 0 \\
\hline ...Sales & 0.08 & & 0 \\
\hline ...Administrative & 0.13 & & 0 \\
\hline ...Farming & 0.01 & & 0 \\
\hline ...Construction & 0.09 & & 0 \\
\hline ...Production & 0.08 & & 0 \\
\hline Transport & 0.06 & & 0 \\
\hline Children in household & & & 0 \\
\hline$\ldots 0$ & 0.53 & & 0 \\
\hline$\ldots 1$ & 0.19 & & 0 \\
\hline$\ldots 2$ & 0.19 & & 0 \\
\hline$\ldots 3+$ & 0.09 & & 0 \\
\hline Employer type & & & 0 \\
\hline ...Private sector & 0.74 & & 0 \\
\hline ...Government & 0.19 & & 0 \\
\hline ...Nonprofit & 0.07 & & 0 \\
\hline
\end{tabular}


Table 4: Quasipoission models of the percent change in coworker sociability at work by work characteristics

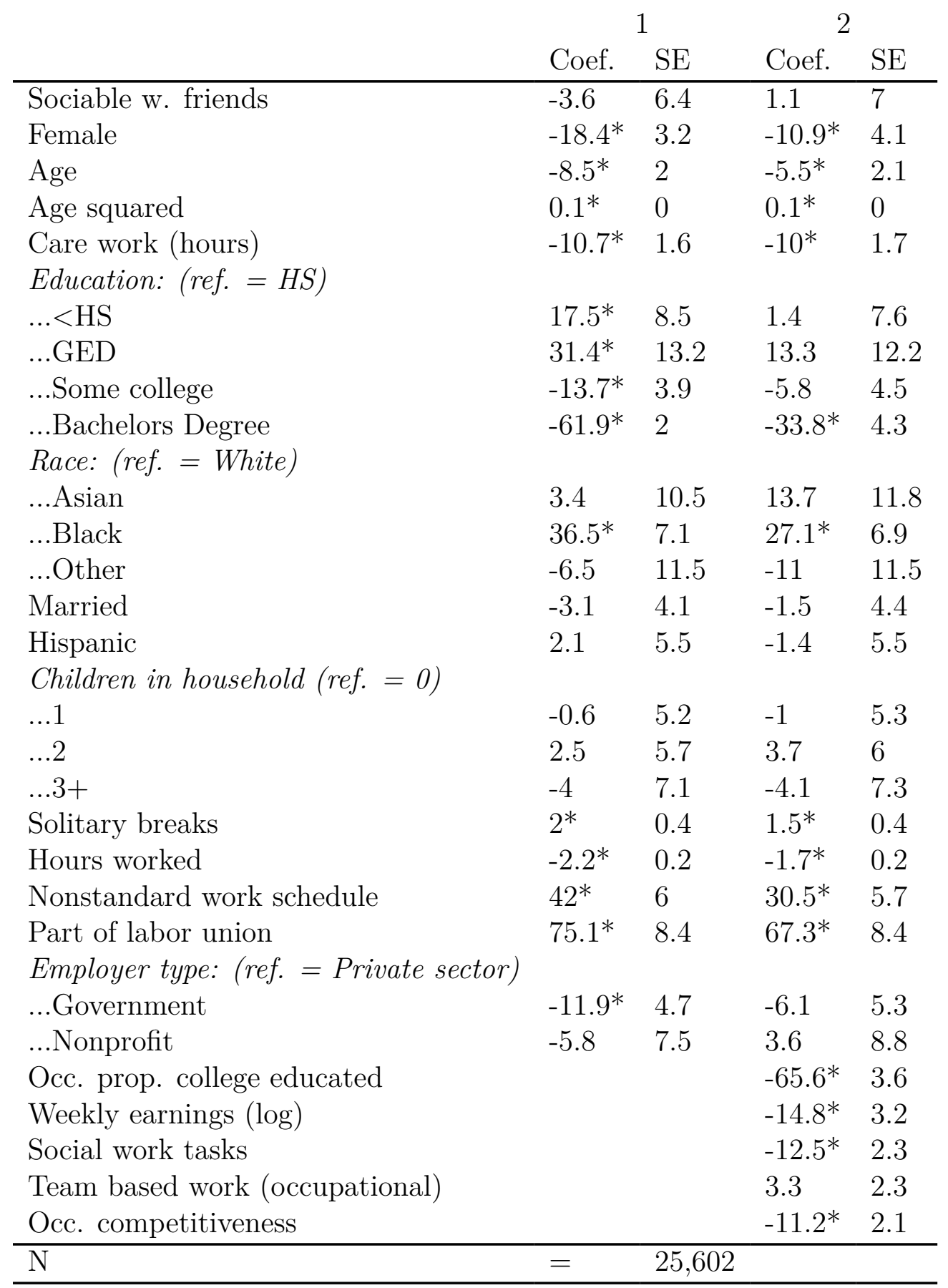

Controls not shown: year and weekday (all models); detailed occupation (Model 2), detailed industry (Model 3). ${ }^{*}=$ p. $<0.05$ 
Table 5: Quasipoission models of the percent change in coworker sociability outside work by work characteristics

\begin{tabular}{|c|c|c|c|c|}
\hline & \multicolumn{2}{|c|}{1} & \multicolumn{2}{|c|}{2} \\
\hline & Coef. & SE & Coef. & $\mathrm{SE}$ \\
\hline Sociable w. friends & 13.6 & 9.4 & 16 & 11.1 \\
\hline Female & $-24^{*}$ & 4.5 & $-23.5^{*}$ & 5.6 \\
\hline Age & -1.2 & 3.4 & -4.8 & 3.8 \\
\hline Age squared & 0 & 0 & 0 & 0 \\
\hline Care work (hours) & $-17.2^{*}$ & 2.1 & $-16.9 *$ & 2.4 \\
\hline Education: (ref. $=H S)$ & & & & \\
\hline$\ldots<\mathrm{HS}$ & 6.2 & 17.4 & $43.1^{*}$ & 25.9 \\
\hline ...GED & 22 & 31.1 & 11.1 & 32.4 \\
\hline ...Some college & $43^{*}$ & 13.5 & $36.7^{*}$ & 14.8 \\
\hline ...Bachelors Degree & $94.3^{*}$ & 17 & $68.6^{*}$ & 19.6 \\
\hline Race: (ref. = White) & & & & \\
\hline ...Asian & 5.7 & 13.5 & -3.9 & 14 \\
\hline ...Black & -10.6 & 8.4 & -6.2 & 10.1 \\
\hline ...Other & $-40.6^{*}$ & 14.2 & -39.4 & 16.4 \\
\hline Married & 8.1 & 7.2 & -2.6 & 7.9 \\
\hline Hispanic & 6.2 & 9.6 & 5 & 10.8 \\
\hline Children in household (ref. =0) & & & & \\
\hline$\ldots 1$ & $-20.7^{*}$ & 6.4 & $-18.4^{*}$ & 7.5 \\
\hline$\ldots 2$ & -14.8 & 7.2 & -10.5 & 8.6 \\
\hline$\ldots 3+$ & $-23.2^{*}$ & 8.8 & $-23.1^{*}$ & 10.2 \\
\hline Solitary breaks & -5.6 & 3.3 & -4.9 & 3.7 \\
\hline Hours worked & $0.8^{*}$ & 0.3 & 0.4 & 0.4 \\
\hline Nonstandard work schedule & $-25.7^{*}$ & 5.6 & $-17.3^{*}$ & 7 \\
\hline Part of labor union & -7.6 & 8.3 & -14.2 & 8.8 \\
\hline Employer type: (ref. = Private sector) & & & & \\
\hline ...Government & $18.8^{*}$ & 8.8 & $29 *$ & 11.4 \\
\hline ...Nonprofit & -10.8 & 10 & -11 & 11.7 \\
\hline Occ. prop. college educated & & & -2.4 & 14.3 \\
\hline Weekly earnings (log) & & & $24.2^{*}$ & 10.4 \\
\hline Social work tasks & & & 0.8 & 4 \\
\hline Team based work (occupational) & & & 0.9 & 4.8 \\
\hline Occ. competitiveness & & & -2.6 & 4.2 \\
\hline $\mathrm{N}$ & $=$ & 41,848 & & \\
\hline
\end{tabular}

Controls not shown: year, weekday, and workday (all models); detailed occupation (Model 2), detailed industry and family income (3). ${ }^{*}=$ p. $<0.05$ 
Table 6: Linear Models of Earnings ( $\log \$$ ) by

Individual and Occupational Sociability At

Work

\begin{tabular}{|c|c|c|c|c|c|c|c|c|}
\hline & \multicolumn{2}{|c|}{1} & \multicolumn{2}{|c|}{2} & \multicolumn{2}{|c|}{3} & \multicolumn{2}{|c|}{4} \\
\hline & Coef. & $\mathrm{SE}$ & Coef. & $\mathrm{SE}$ & Coef. & $\mathrm{SE}$ & Coef. & $\mathrm{SE}$ \\
\hline Sociable with coworker & $-0.09^{*}$ & 0.01 & $-0.04^{*}$ & 0.01 & $-0.14^{*}$ & 0.02 & $-0.08^{*}$ & 0.02 \\
\hline Occupational sociality & & & & & $-1.21^{*}$ & 0.06 & $-0.21^{*}$ & 0.07 \\
\hline Sociable w. coworker x Occ. sociability & & & & & $0.73^{*}$ & 0.11 & $0.26^{*}$ & 0.1 \\
\hline Female & $-0.26^{*}$ & 0.01 & $-0.17^{*}$ & 0.01 & $-0.28^{*}$ & 0.01 & $-0.17^{*}$ & 0.01 \\
\hline Age & $0.06^{*}$ & 0 & $0.05^{*}$ & 0 & $0.06^{*}$ & 0 & $0.05^{*}$ & 0 \\
\hline Age squared & $0^{*}$ & 0 & $0 *$ & 0 & $0^{*}$ & 0 & $0^{*}$ & 0 \\
\hline Care work & 0 & 0 & 0 & 0 & 0 & 0 & 0 & 0 \\
\hline Sociable with friend & 0.02 & 0.01 & 0.01 & 0.01 & 0.02 & 0.01 & 0.01 & 0.01 \\
\hline Education: (ref. $=H S)$ & & & & & & & & \\
\hline$\ldots<\mathrm{HS}$ & $-0.29^{*}$ & 0.02 & $-0.21^{*}$ & 0.02 & $-0.26^{*}$ & 0.02 & $-0.21^{*}$ & 0.02 \\
\hline ...GED & $-0.16^{*}$ & 0.02 & $-0.14^{*}$ & 0.02 & $-0.16^{*}$ & 0.02 & $-0.14^{*}$ & 0.02 \\
\hline ...Some college & $0.16^{*}$ & 0.01 & $0.11^{*}$ & 0.01 & $0.14^{*}$ & 0.01 & $0.11^{*}$ & 0.01 \\
\hline ...Bachelors Degree & $0.55^{*}$ & 0.01 & $0.31^{*}$ & 0.01 & $0.48^{*}$ & 0.01 & $0.31^{*}$ & 0.01 \\
\hline Race (ref. = White) & & & & & & & & \\
\hline ...Asian & $0.08^{*}$ & 0.02 & $0.06^{*}$ & 0.01 & $0.08^{*}$ & 0.02 & $0.06^{*}$ & 0.01 \\
\hline ...Black & $-0.16^{*}$ & 0.01 & $-0.1^{*}$ & 0.01 & $-0.14^{*}$ & 0.01 & $-0.1^{*}$ & 0.01 \\
\hline ...Other & $-0.05^{*}$ & 0.02 & $-0.04^{*}$ & 0.02 & $-0.05^{*}$ & 0.02 & $-0.04^{*}$ & 0.02 \\
\hline Married & $0.07^{*}$ & 0.01 & $0.05^{*}$ & 0.01 & $0.06^{*}$ & 0.01 & $0.05^{*}$ & 0.01 \\
\hline Hispanic & $-0.17^{*}$ & 0.01 & $-0.13^{*}$ & 0.01 & $-0.17^{*}$ & 0.01 & $-0.13^{*}$ & 0.01 \\
\hline Children in household (ref. =0) & & & & & & & & \\
\hline$\ldots 1$ & -0.01 & 0.01 & -0.01 & 0.01 & -0.01 & 0.01 & -0.01 & 0.01 \\
\hline$\ldots 2$ & $0.03^{*}$ & 0.01 & 0.02 & 0.01 & $0.03^{*}$ & 0.01 & 0.02 & 0.01 \\
\hline$\ldots 3+$ & 0.02 & 0.01 & $0.02^{*}$ & 0.01 & 0.02 & 0.01 & $0.02^{*}$ & 0.01 \\
\hline Solitary work breaks & & & $0^{*}$ & 0 & & & $0^{*}$ & 0 \\
\hline Occ. proportion college educated & & & $0.45^{*}$ & 0.02 & & & $0.44^{*}$ & 0.02 \\
\hline Hours worked & & & $0.01^{*}$ & 0 & & & $0.01^{*}$ & 0 \\
\hline Nonstandard work schedule & & & $-0.06^{*}$ & 0.01 & & & $-0.06^{*}$ & 0.01 \\
\hline Social work tasks & & & $-0.06^{*}$ & 0 & & & $-0.06^{*}$ & 0 \\
\hline Team based work (occupational) & & & $0.02^{*}$ & 0 & & & $0.02^{*}$ & 0 \\
\hline Occ. competition & & & $0.07^{*}$ & 0 & & & $0.07^{*}$ & 0 \\
\hline Part of labor union & & & $0.17^{*}$ & 0.01 & & & $0.18^{*}$ & 0.01 \\
\hline Employer type: (ref. = Private sector) & & & & & & & & \\
\hline ...Government & & & $-0.07^{*}$ & 0.01 & & & $-0.07^{*}$ & 0.01 \\
\hline ...Nonprofit & & & $-0.09 *$ & 0.01 & & & $-0.1^{*}$ & 0.01 \\
\hline $\mathrm{N}$ & $=$ & 25,602 & & & & & & \\
\hline
\end{tabular}

Controls not shown: year and weekday. ${ }^{*}=$ p. $<0.05$ 
Table 7: Linear Models of Earnings ( $\log \$)$ by

Individual and Occupational Sociability

Outside Work

\begin{tabular}{|c|c|c|c|c|c|c|c|c|}
\hline & \multicolumn{2}{|c|}{1} & \multicolumn{2}{|c|}{2} & \multicolumn{2}{|c|}{3} & \multicolumn{2}{|c|}{4} \\
\hline & Coef. & $\mathrm{SE}$ & Coef. & $\mathrm{SE}$ & Coef. & $\mathrm{SE}$ & Coef. & $\mathrm{SE}$ \\
\hline Sociable with coworker & $0.04^{*}$ & 0.01 & $0.04^{*}$ & 0.01 & 0.01 & 0.02 & 0 & 0.02 \\
\hline Occupational sociality & & & & & $2.31^{*}$ & 0.09 & $0.73^{*}$ & 0.09 \\
\hline Sociable w. coworker x Occ. sociability & & & & & 0 & 0.4 & 0.56 & 0.38 \\
\hline Female & $-0.24^{*}$ & 0 & $-0.18^{*}$ & 0 & $-0.22^{*}$ & 0 & $-0.17^{*}$ & 0 \\
\hline Care work & $0^{*}$ & 0 & 0 & 0 & $0^{*}$ & 0 & 0 & 0 \\
\hline Age & $0.03^{*}$ & 0 & $0.03^{*}$ & 0 & $0.03^{*}$ & 0 & $0.03^{*}$ & 0 \\
\hline Age squared & $0 *$ & 0 & $0 *$ & 0 & $0^{*}$ & 0 & $0^{*}$ & 0 \\
\hline Sociable with friend & $0.03^{*}$ & 0.01 & $0.02^{*}$ & 0.01 & $0.03^{*}$ & 0.01 & $0.02^{*}$ & 0.01 \\
\hline Education: (ref. $=H S)$ & & & & & & & & \\
\hline$\ldots<\mathrm{HS}$ & $-0.13^{*}$ & 0.01 & $-0.09^{*}$ & 0.01 & $-0.12^{*}$ & 0.01 & $-0.09^{*}$ & 0.01 \\
\hline ...GED & $-0.05^{*}$ & 0.02 & $-0.05^{*}$ & 0.02 & $-0.05^{*}$ & 0.02 & $-0.05^{*}$ & 0.02 \\
\hline ...Some college & $0.08^{*}$ & 0.01 & $0.07^{*}$ & 0.01 & $0.07 *$ & 0.01 & $0.07^{*}$ & 0.01 \\
\hline ...Bachelors Degree & $0.29^{*}$ & 0.01 & $0.19^{*}$ & 0.01 & $0.26^{*}$ & 0.01 & $0.19^{*}$ & 0.01 \\
\hline Race (ref. = White) & & & & & & & & \\
\hline ...Asian & $0.06^{*}$ & 0.01 & $0.04^{*}$ & 0.01 & $0.07^{*}$ & 0.01 & $0.04^{*}$ & 0.01 \\
\hline ...Black & $-0.05^{*}$ & 0.01 & $-0.03^{*}$ & 0.01 & $-0.04^{*}$ & 0.01 & $-0.03^{*}$ & 0.01 \\
\hline ...Other & -0.02 & 0.01 & -0.02 & 0.01 & -0.01 & 0.01 & -0.02 & 0.01 \\
\hline Married & $-0.19^{*}$ & 0.01 & $-0.16^{*}$ & 0.01 & $-0.18^{*}$ & 0.01 & $-0.16^{*}$ & 0.01 \\
\hline Hispanic & $-0.07^{*}$ & 0.01 & $-0.05^{*}$ & 0.01 & $-0.07^{*}$ & 0.01 & $-0.05^{*}$ & 0.01 \\
\hline Children in household (ref. $=0)$ & & & & & & & & \\
\hline$\ldots 1$ & $0.02^{*}$ & 0.01 & $0.02^{*}$ & 0.01 & $0.02 *$ & 0.01 & $0.02^{*}$ & 0.01 \\
\hline$\ldots 2$ & $0.05^{*}$ & 0.01 & $0.05^{*}$ & 0.01 & $0.05^{*}$ & 0.01 & $0.05^{*}$ & 0.01 \\
\hline$\ldots 3+$ & $0.08^{*}$ & 0.01 & $0.08^{*}$ & 0.01 & $0.08^{*}$ & 0.01 & $0.08^{*}$ & 0.01 \\
\hline Solitary work breaks & & & 0 & 0 & & & 0 & 0 \\
\hline Occ. prop. college educated & & & $0.26^{*}$ & 0.01 & & & $0.25^{*}$ & 0.01 \\
\hline Hours worked & & & $0.01^{*}$ & 0 & & & $0.01^{*}$ & 0 \\
\hline Social work tasks & & & $-0.04^{*}$ & 0 & & & $-0.04^{*}$ & 0 \\
\hline Nonstandard work schedule & & & $-0.03^{*}$ & 0.01 & & & $-0.03^{*}$ & 0.01 \\
\hline Team based work (occupational) & & & $0.02^{*}$ & 0 & & & $0.02^{*}$ & 0 \\
\hline Occ. competition & & & $0.05^{*}$ & 0 & & & $0.04^{*}$ & 0 \\
\hline Part of labor union & & & $0.13^{*}$ & 0.01 & & & $0.13^{*}$ & 0.01 \\
\hline Employer type: (ref. = Private sector) & & & & & & & & \\
\hline ...Government & & & $-0.04^{*}$ & 0.01 & & & $-0.04^{*}$ & 0.01 \\
\hline ...Nonprofit & & & $-0.05^{*}$ & 0.01 & & & $-0.05^{*}$ & 0.01 \\
\hline $\mathrm{N}$ & $=$ & 41,848 & & & & & & \\
\hline
\end{tabular}

Controls not shown: year, weekday, workday and family income. ${ }^{*}=$ p. $<0.05$ 
Figures 


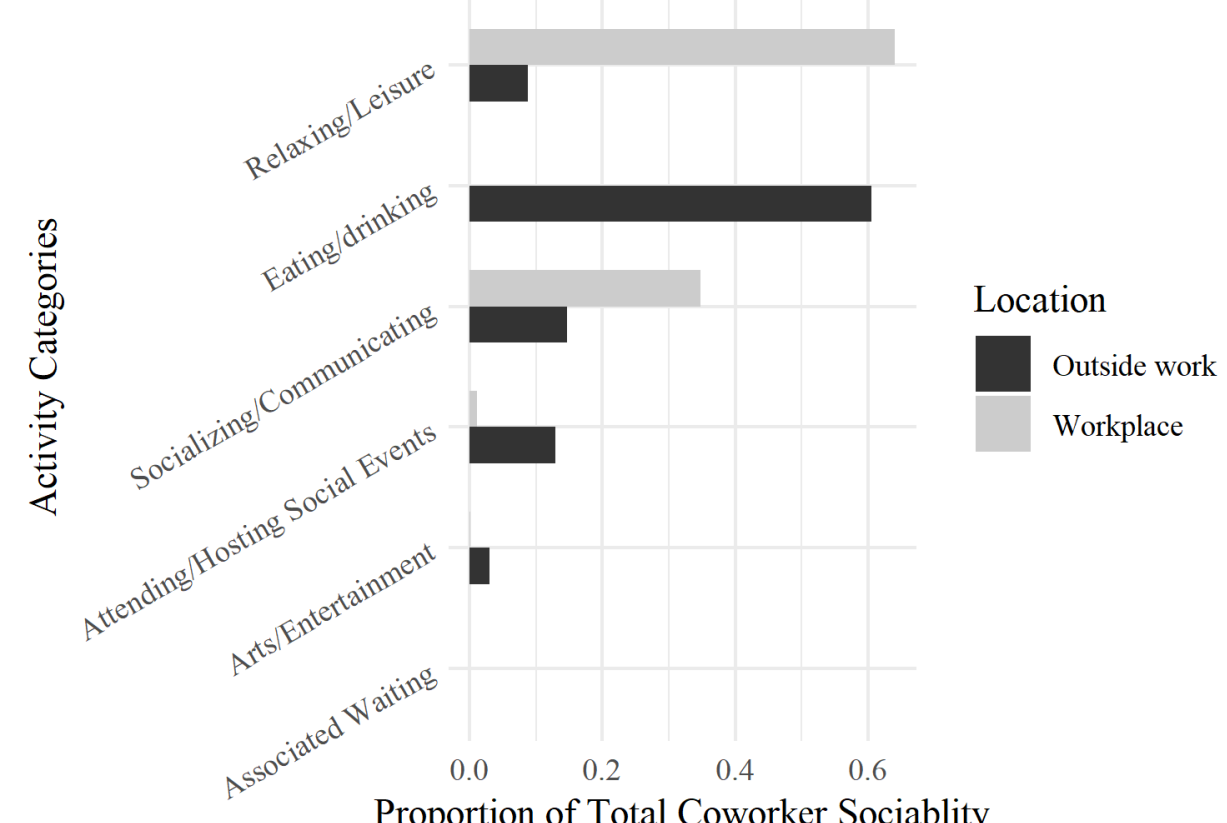

Proportion of Total Coworker Sociablity

Data: ATUS, 2003-2016, $\mathrm{n}=22,428$ activities

Figure 1: Activity Components of Coworker Sociability in and Outside of the Workplace

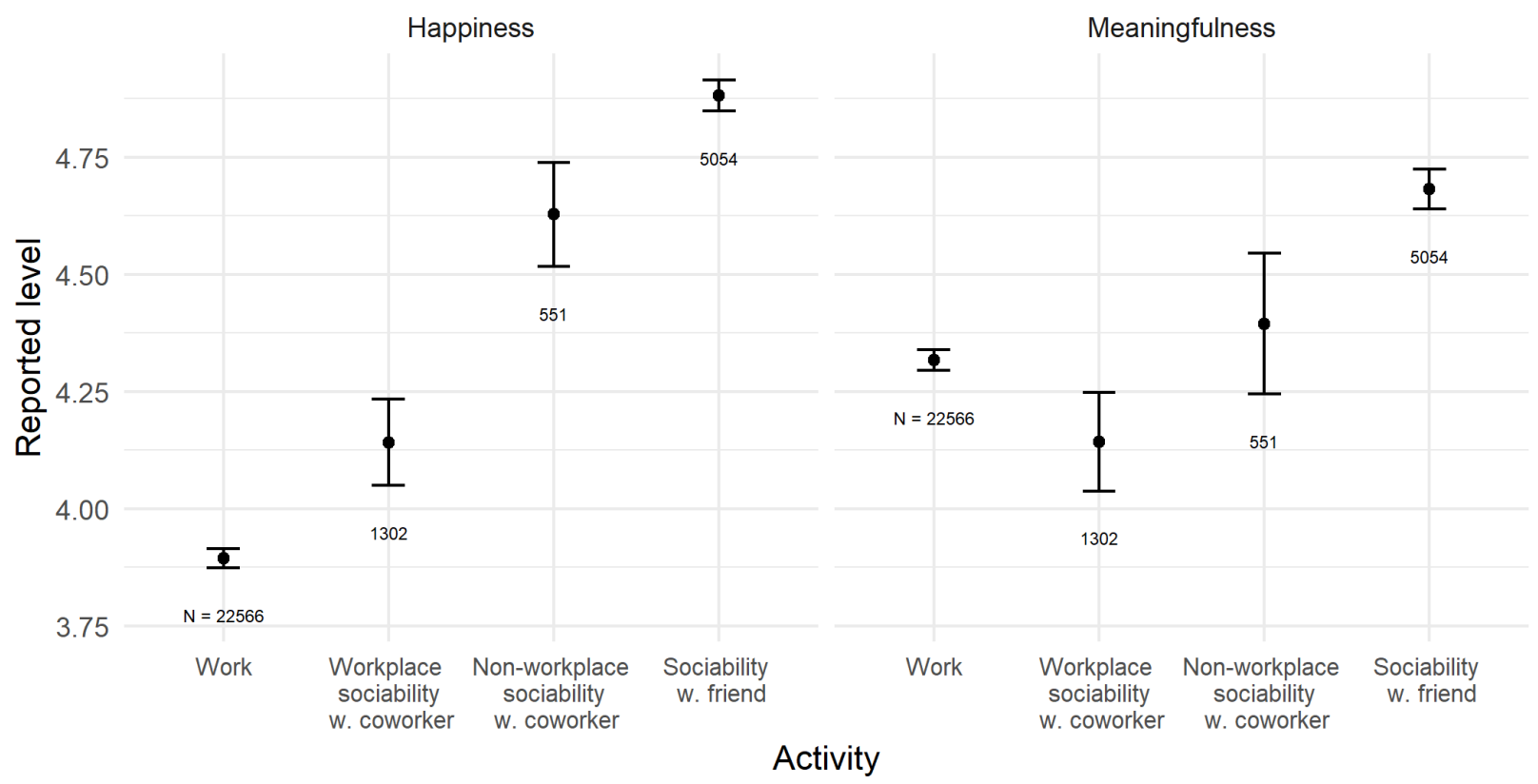

Data: Employed respondents in the ATUS wellbeing module. Error bars report 95\% Cls.

Figure 2: Affect during Work, Coworker Sociability, and Socializing with Friends. 


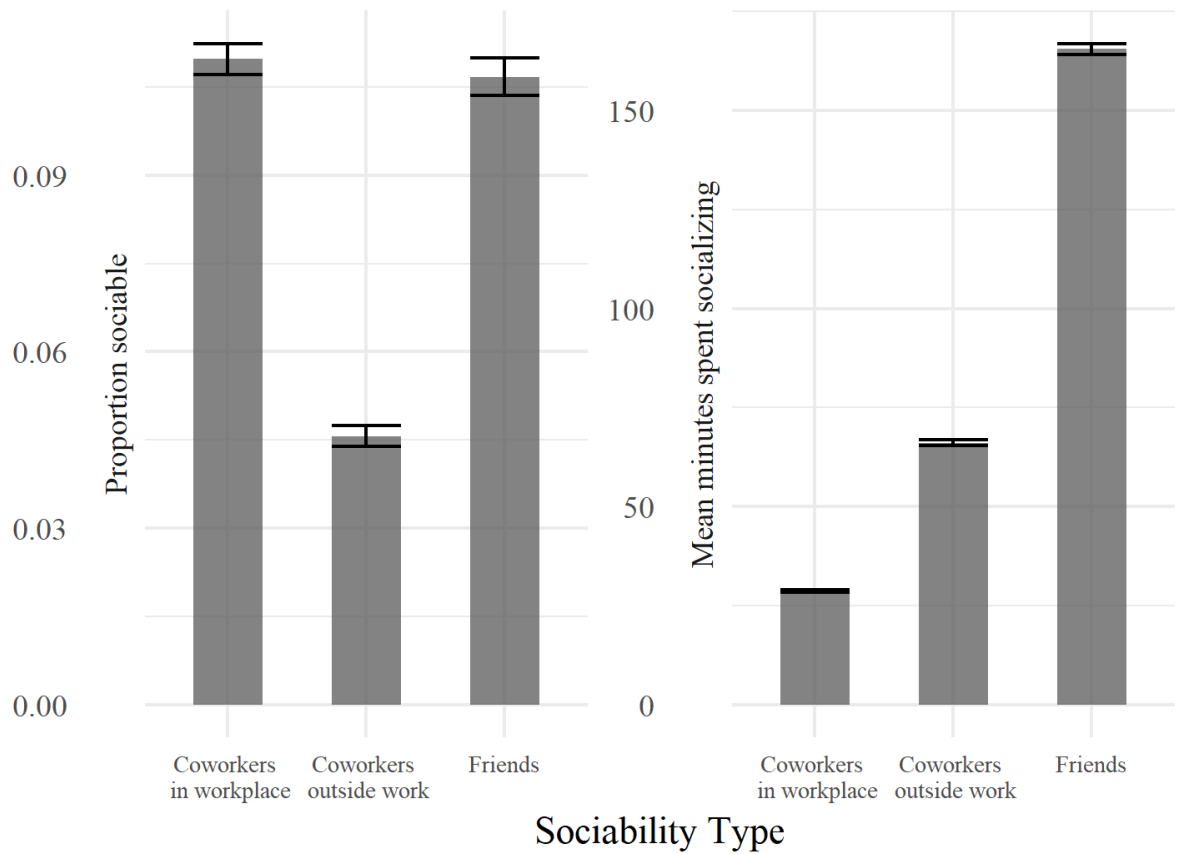

Data: Employed ATUS respondents, 25-55, $\mathrm{n}=41,848$. Error bars report 95\% CIs.

Figure 3: Proportion of Workers who Socialize, and Mean Duration Sociable, Conditional on Socializing. 

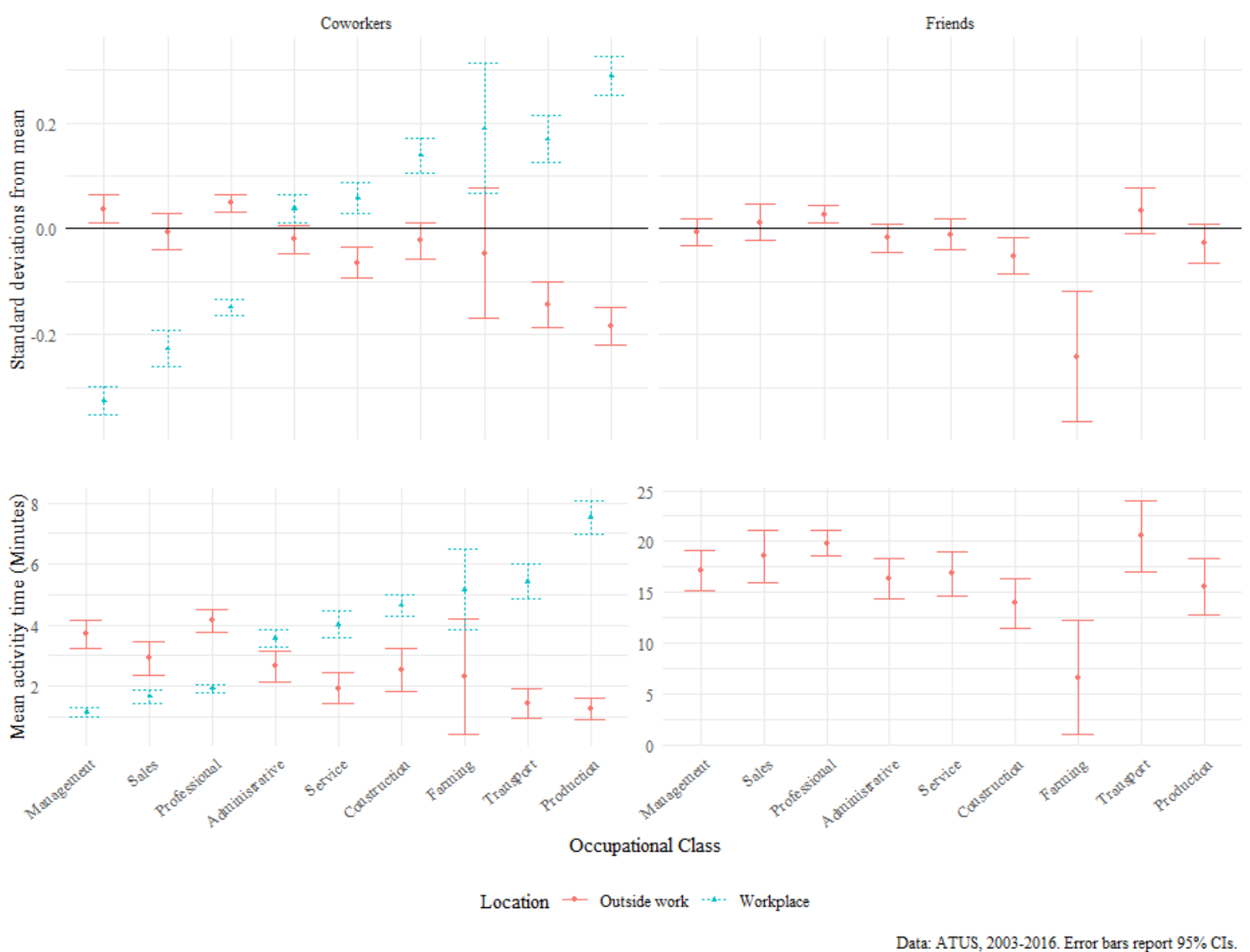

Figure 4: Sociability with Friends and Coworkers by Broad Occupational Class 


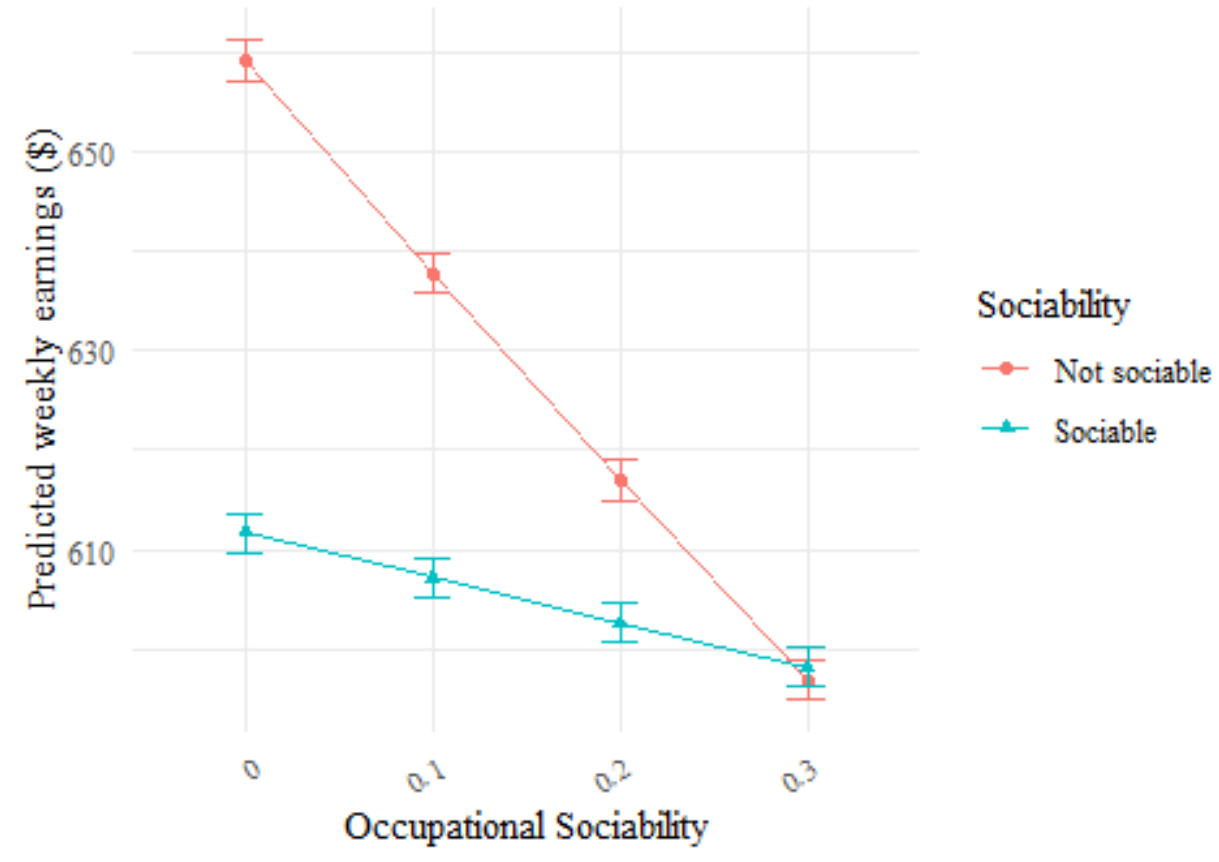

Data: ATUS, 2003-2016. Predicted values from Table 7, Model 4.

Figure 5: Predicted weekly earnings by Individual and Occupational Coworker Sociability in the Workplace 